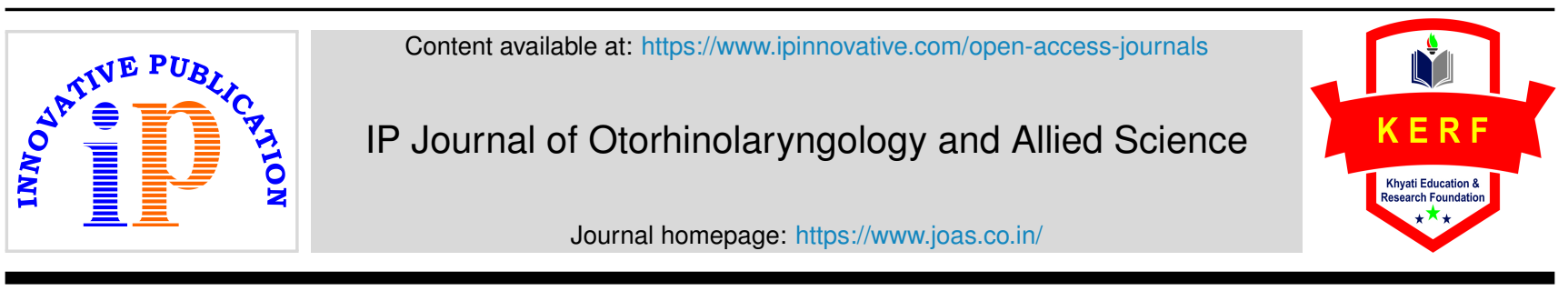

Original Research Article

\title{
Clinico-Etiological study of benign lesions of pinna and its management
}

\author{
Tejaswini Honnegowda ${ }^{1}$, Nagarathna Hosalli Kumaraswamy ${ }^{1, *}$, Sumit Kumar Gaur ${ }^{2}$ \\ ${ }^{1}$ Dept. of ENT, Akash Institute of Medical Sciences and Research Centre, Devanahalli, Bengaluru, Karnataka, India \\ ${ }^{2}$ Dept. of ENT and Head \& Neck Surgery, Apollo International Hospital, Bannerghatta Road, Bengaluru, Karnataka, India
}

\section{A R T I C L E I N F O}

\section{Article history:}

Received 28-01-2021

Accepted 06-02-2021

Available online 20-04-2021

Keywords:

Benign lesions

Keloid

Pseudocyst of auricle

Perichondritis

Herpes Zoster Oticus

\begin{abstract}
A B S T R A C T
Introduction : The lesions of pinna are not uncommon. Pinna, a delicate, vulnerable structure is more liable for trauma. The present study aimed to examine the various types of benign lesions of pinna and management with appropriate intervention.

Materials and Methods : This prospective study was conducted for a period of 2 years in Department of ENT of our medical college Hospital, Bengaluru, Karnataka, India. A total of 140 subjects were examined in this study from ENT out patient department. The patients with various benign lesions of pinna were included in this study. A detailed clinical history regarding onset, predisposing factors and associated conditions were collected. Routine blood and urine examination were done. Depending on the type of lesion patients were managed conservatively or surgically.

Results: A total of 140 subjects were examined in this study. Majority of the patients were in the age group of 21-30 years. i.e. 61(44\%) patients, followed by 29(21\%) were in the 31-40 years. Most of the patients presented with Keloid, 56(39\%), 42 (32\%) cases were Pseudocyst of auricle, 37(26\%) were Perichondritis, Herpes Zoster Oticus and sebaceous cyst were observed in 2 cases each, followed by a case of Neurofibroma. Keloid was more predominant in females than males. Pseudocyst of auricle and Perichondritis were little more in males than female subjects. Keloid was unilateral in $43(77 \%)$ patients and bilateral in $13(23 \%)$ cases. Trauma is the predisposing factor in most of the cases, followed by ear piercing/iatrogenic. Keloid patients were managed with complete excision of the lesion followed by intralesional triamcinolone. Pseudocyst auricle was observed in 42 patients, its prevalence was more in males. Trauma is the main pre-disposing factor. Pseudocyst auricle was managed by aspiration, and by window procedure. Perichondritis was observed in 37 cases, again trauma was the main predisposing factor observed in $54 \%$ cases followed by ear piercing/iatrogenic in $27 \%$ cases. In addition, $78 \%$ cases were managed by incision and drainage and $22 \%$ cases were managed conservatively with broad spectrum antibiotics.

Recurrence in 5\% cases of keloid, $29 \%$ cases of pseudocyst of auricle was observed after complete excision and aspiration respectively.

Conclusion: Our study results conclude that various benign lesions of pinna such as keloid, pseudocyst of auricle, perichondritis, Herpes Zoster Oticus, sebaceous cyst, and neurofibroma of pinna can be managed conservatively or surgically. Trauma is the most important predisposing factor in majority of the lesions. Diabetes Mellitus plays a pivotal role in the prognosis of perichondritis and Herpes Zoster Oticus.
\end{abstract}

(C) This is an open access article distributed under the terms of the Creative Commons Attribution License (https://creativecommons.org/licenses/by/4.0/) which permits unrestricted use, distribution, and reproduction in any medium, provided the original author and source are credited.

\footnotetext{
* Corresponding author.

E-mail address: nagarathnahk@gmail.com (N. H. Kumaraswamy).
}

\section{Introduction}

Pinna, being the important part of peripheral auditory system, functions to conduct sound waves in the form of vibrations to tympanic membrane. ${ }^{1,2}$ Pinna adds to facial aesthetics. The lesions of pinna are not uncommon. 
Pinna, a delicate, vulnerable structure is more liable for trauma, and its incidence is more commonly reported due to increasing violence, accidents, and high ear piercing. Delay in diagnosis and improper management leads to disfigurement and cosmetic deformity of the pinna. ${ }^{3}$

Keloid characterized by smooth, pink, rounded scar-like tumour that invariably follows trauma or incision on the skin. ${ }^{1}$ Keloids are commonly prone for recurrence with need for long time treatment. ${ }^{4}$ Pseudocyst of auricle is also called as auricular seroma, is a swelling with serous fluid collection between perichondrium and cartilage. It is usually seen in the upper part of auricle. However, the aetiology of seroma is unknown. Based on the swelling and symptoms, seromas of auricle can be differentiated from other lesions of pinna. Because of its high chances of recurrence, successful treatment is challenging. 5,6

Perichondritis, an infection involving cartilage and subcutaneous tissue and it produces swelling which can be severe, and it may lead to focal ear necrosis. The symptoms of perichondritis include pain, erythema, and local warmth. The initial complaint is often a dull ache. ${ }^{7}$ Herpes Zoster Oticus is defined as acute peripheral facial neuropathy caused by reactivated latent varicella zoster virus (VZV) in geniculate ganglion, characterized by erythematous vesicular rash of the skin of the ear canal, auricle, facial skin, oral mucosa and facial palsy. ${ }^{8}$ Sebaceous cyst is a benign cyst due to blockage of draining ducts of sebaceous glands leads to cystic dilatation of gland as a result of sebum accumulation. Around the auricle, retention or epidermal cyst is commonly seen, specifically on postauricular sulcus and lobule, because of high sebaceous glands. Some may also arise from hair follicle. ${ }^{1}$

Neurofibroma are the common lesions of the nervous system. They can arise in all peripheral nerve elements. However, few cases involving neurofibroma have been reported. ${ }^{9,10}$ The present study aimed to examine the various types of benign lesions of pinna and management with appropriate intervention.

\section{Materials and Methods}

This prospective study was conducted for a period of 2years in Department of ENT of our medical college Hospital, Bengaluru, Karnataka, India. After approval from the Institutional Ethics Committee and Informed consent from study subjects, a total of 140 subjects were examined from ENT out patient department. Males, females, all age groups with various benign lesions of Pinna were included in this study. Patients with congenital lesions, disorders primarily affecting the external auditory canal or the middle ear and malignant conditions were excluded from the study.

A detailed clinical history regarding onset, predisposing factors and associated conditions were collected. Routine blood and urine examination were done for all subjects. In addition to this, culture was done in relevant cases.
Depending on the type of lesion patients were managed conservatively or surgically.

\section{Results}

A total of 140 subjects were examined in this study from ENT out patient department. In this study, 61 (44\%) patients were in age group of 21-30 years, followed by 29(21\%) were in the $31-40$ years, and $23(16 \%)$ were in the $11-20$ years of age group and $76(54 \%)$ were females and 64 (46\%) were males as shown in Table 1.

In the present study, most of the patients presented with Keloid, 56(39\%), 42(32\%) cases were Pseudocyst of auricle, 37(26\%) were Perichondritis, Herpes Zoster Oticus and sebaceous cyst were observed in 2 cases each, followed by a case of Neurofibroma as shown in Table 2 .

Keloid was more predominant in females than males. Pseudocyst of auricle and Perichondritis were little more in males than female subjects as shown in Table 3. In addition, Keloid was unilateral in $43(77 \%)$ patients and bilateral in $13(23 \%)$ cases.

Predisposing factors for keloid such as trauma $8(14 \%)$, ear piercing/iatrogenic 37(66\%), Burns 2(4\%), unknown 9(16\%) was observed as illustrated in Table 4. Concerned with Keloid management, 53(95\%) were managed with complete excision of the lesion followed by intralesional triamcinolone and 5 cases were treated with intralesional triamcinolone alone.

Pseudocyst auricle was observed in 42 patients, its prevalence was more in males than females. Trauma is the main pre-disposing factor, seen in 29 cases followed by Diabetes mellitus in 3 and unknown in 10 patients as shown in Table 5. In addition, management of Pseudocyst auricle, 42 cases were managed by aspiration and 13 were by window procedure. Out 42 cases, 29(69\%) responded to treatment with wide bore aspiration and pressure dressing and rest of the cases were treated with window procedure.

Perichondritis was observed in 37 cases. Trauma was the main factor observed in 20(54\%) cases followed by ear piercing/iatrogenic in $10(27 \%)$ cases and diabetes mellitus in $5(14 \%)$, unknown in $2(5 \%)$ cases respectively as shown in table 6. In addition, 29 cases $(78 \%)$ were managed by incision and drainage and $8(22 \%)$ cases were treated conservatively with broad spectrum antibiotics.

$3(5 \%)$ cases of keloid, $12(29 \%)$ cases of pseudocyst of auricle recurred after complete excision and aspiration respectively. 4 cases of perichondritis had thickening and deformity of pinna.

\section{Discussion}

Pinna contributes to the facial contour, any lesion in the pinna drastically alters the appearance. Pinna is a delicate, protruding structure, made of elastic cartilage which makes it more liable for trauma and may lead to hematoma, 
Table 1: Demographic details of patients

\begin{tabular}{lcc}
\hline Age in years & No. of cases & Percentage \\
$0-10$ yrs & 1 & $<1$ \\
$11-20$ & 23 & 16 \\
$21-30$ & 61 & 44 \\
$31-40$ & 29 & 21 \\
$41-50$ & 19 & 13 \\
$51-60$ & 7 & 5 \\
\hline
\end{tabular}

Table 2: Distribution of total cases

\begin{tabular}{lcc}
\hline Diagnosis & $\begin{array}{c}\text { No. of } \\
\text { cases }\end{array}$ & Percentage \\
Keloid & 56 & 39 \\
Pseudocyst of auricle & 42 & 32 \\
Perichondritis & 37 & 26 \\
Herpes Zoster Oticus & 02 & 1 \\
Sebaceous cyst & 2 & 1 \\
Neurofibroma & 1 & $<1$ \\
Total & 140 & $100 \%$ \\
\hline
\end{tabular}

Table 3: Sex distribution

\begin{tabular}{lcc}
\hline Diagnosis & Male & Female \\
Keloid & $13(23 \%)$ & $43(77 \%)$ \\
Pseudocyst of auricle & $26(62 \%)$ & $16(38 \%)$ \\
Perichondritis & $20(54 \%)$ & $17(46 \%)$ \\
\hline
\end{tabular}

Table 4: Pre-disposing factors for Keloid

\begin{tabular}{lcc}
\hline Pre-disposing Factors & Number & Percentage \\
Trauma & 8 & $14 \%$ \\
Ear piercing/iatrogenic & 37 & $66 \%$ \\
Burns & 2 & $4 \%$ \\
Unknown & 9 & $16 \%$ \\
Total & 56 & 100 \\
\hline
\end{tabular}

Table 5: Pre-disposing factors forPseudocyst of auricle

\begin{tabular}{lcc}
\hline Pre-disposing Factors & Number & Percentage \\
Trauma & 29 & $69 \%$ \\
Diabetes mellitus & 3 & $7 \%$ \\
Unknown & 10 & $24 \%$ \\
Total & 42 & 100 \\
\hline
\end{tabular}

Table 6: Predisposing factors forperichondritis

\begin{tabular}{lcc}
\hline Pre-disposing Factors & Number & Percentage \\
Trauma & 20 & $54 \%$ \\
Ear piercing/iatrogenic & 10 & $27 \%$ \\
Diabetes mellitus & 5 & $14 \%$ \\
Unknown & 2 & $5 \%$ \\
Total & 37 & 100 \\
\hline
\end{tabular}

perichondritis, seroma, etc. ${ }^{3}$ In the present study, 61(44\%) patients were in age group of 21-30 years. In the above age group, people are more concerned about their cosmetic appearance, since pinna is important part of facial aesthesis. In this study, 76(54\%) were females and 64(46\%) were males. In our study, 86(61\%) cases were low income status, and $50(36 \%)$ cases were belonging to middle class and only $4(3 \%)$ were in upper class. Assessment of socio-economic status was based on modified Kuppuswamy scale. It was known that lesions of pinna are common in low- and middleclass people due to low hygiene conditions. ${ }^{1}$

The most common finding in this study was Keloid, observed in 56 (39\%). The increased prevalence of keloid could be due to increase in the high ear piercing. i.e. ear piercing in cartilaginous part of pinna, considered as fashion and tradition. Compared to males, females were more affected with keloid, this may be due to custom of ear piercing in Indians. Keloids usually depends on the ear-piercing site and also has genetic involvement. ${ }^{1}$ Trauma 14\%, ear piercing/iatrogenic $66 \%$ are the most common predisposing factors associated with keloid. Most of the patients with keloid $95 \%$ were managed with complete excision of the lesion followed by intralesional triamcinolone.

In a retrospective study conducted by Daniel J Rosen, et al. involving 64 patients with 92 ear keloids, treatment consisted of excision with an intraoperative and two postoperative steroid injections and the success rate was reported to be $80 \% .^{11}$

In our study, pseudocyst auricle was observed in 42 patients, its prevalence was more in males than females. Trauma is the main pre-disposing factor than others. Most of the Pseudocyst auricle cases managed by aspiration and 13 were by window procedure. Out of 42 cases of pseudocyst auricle, $69 \%$ were responded to aspiration and pressure dressing and $30 \%$ were treated with window procedure. Recurrence was observed in 3 cases following aspiration. All cases were treated successfully by following window procedure. In a study conducted by Monika Shamrao Malgonde et al, involving 20 patients with auricular seromas reported that aspiration and splint application are the very simple and effective in the management of seromas and it prevents patient distress from fluid recollection and social embarrassment. $^{5}$

Similarly, Lim et al, conducted a retrospective study on pseudocyst of auricle involving 9 patients who were treated by simple aspiration of the cyst had prompt re-accumulation of the pseudocyst, reported that none of the patients had recurrence after excision and compression buttoning. ${ }^{12}$ Perichondritis was observed in 37 cases. Trauma was the main factor observed in $20(54 \%)$ cases followed by ear piercing/iatrogenic in $10(27 \%)$ cases and diabetes mellitus in $5(14 \%)$, unknown in $2(5 \%)$ cases respectively. The commonest cause of perichondritis is blunt trauma with a 
subsequent hematoma and secondary infection. However, penetrating trauma can be an inciting cause and may introduce an infection directly. Piercing of the ear, involving punctures of the cartilage have been associated with pinna panniculitis. Similar to this study, Prasad et al, conducted a study on series of 61 cases of perichondritis, and reported that the common factor associated with Perichondritis was trauma. ${ }^{13}$

Most of the cases of Perichondritis, $78 \%$ were managed by incision and drainage and $22 \%$ cases were managed conservatively with antibiotics. In our study, Herpes Zoster Oticus observed in only 2 cases and was managed conservatively. It was believed that this virus infects the facial nerve near the inner ear, causing irritation and swelling of the nerve. This is usually seen in older people (> 60 years). The incidence and severity of the disease is depending on the cellular immunity of the patient. Therefore, elderly patients should be recognized to prevent this virus risk and apt treatment must be initiated at the earliest. ${ }^{14}$ Sebaceous cysts were observed only in 2 cases and were managed with complete excision.

\section{Conclusion}

Our study results conclude that various benign lesions of pinna such as keloid, pseudocyst of auricle, perichondritis, Herpes Zoster Oticus, sebaceous cyst, and neurofibroma of pinna can be managed conservatively or surgically. Trauma is the most important predisposing factor in majority of the lesions. Diabetes Mellitus plays a pivotal role in the prognosis of perichondritis and Herpes Zoster Oticus. Early diagnosis and timely intervention prevent the complications and cosmetic deformity.

\section{Conflicts of Interest}

All contributing authors declare no conflicts of interest.

\section{Source of Funding}

None.

\section{References}

1. Srirangaprasad K, Kumar P, Patil S, Mahajan R, Nagaraj TM, George $\mathrm{K}$, et al. A clinical study of benign lesions of pinna. J Evolution Med
Dent Sci . 2016;5(10):414-7. do1:10.14260/jemds/2016/95,

2. Chatra PS. Lesions in the external auditory canal. Indian J Radiol Imaging. 2011;21(4):274-8. 10i:-104103/097-302690687

3. Prasad KC, Karthik S, Prasad SC. A comprehensive study on lesions of the pinna. Am J Otolaryngol. 2005;26(1):1-6. do1:10.1016/1.amjoto.2004.04.015.

4. Chaitanya V, Kavitha Y, Basavaraju K, Joish UK. A retrospective study of demographic profile of keloid over the pinna in central Karnataka. Int J Otorhinolaryngol Head Neck Surg. 2018;4(3):726-9. doi:10.18203/1ssn.2454-5929.1johns20181860.

5. Shamraomalgonde M, Kumar M. Auricular seroma: a new concept inManagement. Plast Aesthet Res. 2014;1(1):13-5.

6. Mahes H, Bhat T, Vinay V, Rao D, Rosario. Cruciate Incision for Treatment of Primary/Recurrent Cases of Seroma/Hematoma of Pinna: A Novel Approach. J Clin Diagn Res. 2015;9(2):MC01-MC02.

7. Lucerna A, Espinosa J. Acute atraumatic pinna (auricular) perichondritis. World J Emerg Med. 2018;9(2):152-3. doi:10.5847/wjem.1.1920-8642.2018.02.013.

8. Kannan SK, Sherubin JE, Sajesh S, Gopakumar KP. Ramsay Hunt Syndrome (Herpes Zoster Oticus). J Indian Acad Oral Med Radiol. 2012;24(1):70-2. [01:10.5005//p-journals-10011-1263.

9. Singh S, Tandon S, Lahiri A, Sharma S. Neurofibroma of the Pinna. Int J Otolaryngol Head Neck Surg. 2014;03(02):66-70. doi:10.4236/1johns.2014.32014.

10. Nee TS, Ami M, and MKH. Primuharsa Putra Sabir Husin Athar. Postauricular neurofibroma - a rare occurrence. Braz J Otorhinolaryngol. 2017;83(5):600-1.

11. Rosen DJ, Patel MK, Freeman K, Weiss PR. A Primary Protocol for the Management of Ear Keloids: Results of Excision Combined with Intraoperative and Postoperative Steroid Injections. Plast Reconstr Surg. 2007;120(5):1395-400. doi:10.1097/01.prs.0000279373.25099.2a.

12. Lim CM, Goh YH, Chao SS. Pseudocyst of the auricle. Laryngoscope 2009;112(11):2033-6. 10i: $01097100005537-20021000-00022$

13. Prasad HK, Sreedharan S, Prasad HS, Meyyappan MH, Harsha KS. Perichondritis of the auricle and its management. J Laryngol Otol.

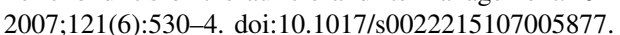

14. Dhavalshankh GP, Dhavalshankh AG, Mhasvekar V. A rare case of Herpes zoster oticus in an immunocompetent patient. Our Dermatol Online. 2012;3(4):349-51. 10:-10/24//ourd20124.78

\section{Author biography}

Tejaswini Honnegowda, Associate Professor

Nagarathna Hosalli Kumaraswamy, Assistant Professor

Sumit Kumar Gaur, Senior Consultant

Cite this article: Honnegowda T, Kumaraswamy NH, Gaur SK.

Clinico-Etiological study of benign lesions of pinna and its

management. IP J Otorhinolaryngol Allied Sci 2021;4(1):24-27. 